\title{
Crop correlations with structure elements in varieties of grain sorghum of various ecological and geographical origin
}

\author{
Alexander Baranovskiy ${ }^{1, *}$, Nikolay Konoplya ${ }^{2}$, Tatyana Kosogova ${ }^{2}$, Sergey Kapustin ${ }^{3,4}$, and \\ Andrey Kapustin ${ }^{5}$ \\ ${ }^{1}$ SEI LPR Lugansk State Agrarian University, 91008 Lugansk, Ukraine \\ ${ }^{2}$ SEI HE LPR "Lugansk State Pedagogical University", 91011, Lugansk, Ukraine \\ ${ }^{3}$ North-Caucasian Federal Scientific Agrarian Center, 356241 Mikhailovsk, Russia \\ ${ }^{4}$ Stavropol State Agrarian University, 355017 Stavropol, Russia \\ ${ }^{5}$ North Caucasus Federal University, 355017 Stavropol, Russia
}

\begin{abstract}
In the conditions of the Donbass region, 38 varieties of grain sorghum of various ecological and geographical origin-breeding companies of Western Europe ("RAGT SEMENCES", "EURALIS SEMENCES", "PIONEER"), Ukraine, Russia, the international company "ADVANTA", the American company "RICHARDSON SEED" were studied. Field research was carried out in the period from 2016 to 2018 in the experimental field of the Lugansk National Agrarian University on ordinary shallow weakly washed blackearth (chernozem) on loess-loam. It was found that the most adapted and productive $(6,0 \mathrm{t} / \mathrm{ha}$ of grain or more) were early - maturing hybrids - Swift and Queyras; middle early Solarius, PR88Y20, Bianca, Puma Star; mid-season - Bounty. The most productive (5,0 t/ha and more grain) varieties - Odessky 205, Krupinka 10, Darunok, Zersta 97. The average positive correlation between the duration of the growing season of varieties and crop yield was established. The density of the productive stem in the range from 11 to 25 panicles per $1 \mathrm{~m}^{2}$, the length of the panicle leg and the weight of 1000 grains did not have a significant correlation with the level of sorghum yield. Sorghum yield had an average and increased correlation with panicle weight, grain weight per panicle, number of grains per panicle, grain type, and medium negative relationship with plant height.
\end{abstract}

\section{Introduction}

In the conditions of increasing aridity of the climate, the issue of expanding crops of drought-resistant crops with high yield potential and demand on the world market becomes urgent. A promising solution to this problem is the grain sorghum crop, which ranks fifth in the world in terms of production and cultivation area, after wheat, corn, rice and barley. It is cultivated in 85 countries of the world on a total area of 46-50 million hectares with an

\footnotetext{
*Corresponding author: lnau_sorgo2011@mail.ru
} 
annual grain production of 60-70 million tons. The main producers of sorghum grain are the United States, Nigeria, Sudan, Mexico, China, India, Ethiopia, Argentina, Burkina Faso, Brazil and Australia, which account for up to $90 \%$ of gross revenues. Over the past 40-50 years, the area under sorghum cultivation has increased by $50 \%$, and the yield has more than doubled, exceeding the level of $1.5 \mathrm{t} / \mathrm{ha}[4,5,6,9]$.

In the Lugansk region, the weather and climate conditions are quite favorable for growing not only early-maturing, but also medium-maturing varieties and hybrids of grain sorghum, which annually provide a crop yield of 5,0-6,0 t/ha of grain. N.A. Shepel (1994) indicates that, depending on the growing season, for early varieties and hybrids the sum of temperatures in the range of $2000-2400{ }^{\circ} \mathrm{C}$ is required, for mid-season and late-maturing varieties and hybrids $-2800-3500{ }^{\circ} \mathrm{C}$. According to the hydrometeorological center of the city of Lugansk, on average for the period from 2008 to 2019, the sum of active temperatures for the growing season was $3495{ }^{\circ} \mathrm{C}$ (climate norm $-3148{ }^{\circ} \mathrm{C}$ ), the Selyaninov hydrothermal coefficient (HTC) - 0.87 (norm - 1.00), the amount of precipitation for April-September - $270.4 \mathrm{~mm}$ (norm - $309 \mathrm{~mm}$ ). Growing grain sorghum in the arid conditions of the Lugansk region provided a significantly higher grain yield compared to other common spring crops - barley and corn (table 1).

The purpose of the work is to identify the most adapted and high-yielding varieties and hybrids of grain sorghum in different weather conditions in the Lugansk region, as well as the degree of dependence of the grain yield on the main indicators of its structure.

Table 1. Crop area and yield of spring grain crops in the region

\begin{tabular}{|c|c|c|c|c|c|c|}
\hline \multirow{2}{*}{$\begin{array}{l}\text { Average } \\
\text { for 2007- } \\
2019\end{array}$} & \multicolumn{2}{|c|}{ Spring barley } & \multicolumn{2}{c|}{ Grain sorghum } & \multicolumn{2}{c|}{ Grain maize } \\
\cline { 2 - 7 } & $\begin{array}{c}\mathrm{S} \\
\text { (thousan } \\
\mathrm{d} \text { ha) }\end{array}$ & $\begin{array}{c}\text { Crop yield } \\
\text { (t/ha) }\end{array}$ & $\begin{array}{c}\mathrm{S} \\
\text { (thousand } \\
\text { ha) }\end{array}$ & $\begin{array}{c}\text { Crop yield } \\
\text { (t/ha) }\end{array}$ & $\begin{array}{c}\mathrm{S} \\
\text { (thousan } \\
\mathrm{d} \text { ha) }\end{array}$ & $\begin{array}{c}\text { Crop yield } \\
\text { (t/ha) }\end{array}$ \\
\hline $\begin{array}{c}\text { Average } \\
\text { age }\end{array}$ & 65.6 & 1.93 & 9.8 & 3.31 & 64.6 & 2.99 \\
\hline
\end{tabular}

\section{Material and methods of research}

During 2016-2018, grain productivity of modern varieties and hybrids of grain sorghum from various breeding centers was studied at the experimental field of the Lugansk National Agrarian University. The soil of the experimental site is ordinary shallow weakly washed blackearth (chernozem) on loess-loam. Agricultural technology in the experiment was generally accepted for the region. The area of the accounting plot was $25-30 \mathrm{~m}^{2}$, the repetition rate was four times. Sorghum sowing was carried out in optimal agrotechnical terms with a norm of 250-300 thousand/ha of germinating seeds with further formation of seedling density up to $140-150$ thousand/ha of plants. The experiment was carried out in accordance with the generally accepted method of field experiment.

Weather conditions during the research period were quite contrasting. Favorable conditions of vegetation have developed in 2016: amount of precipitation for vegetation period (April-September) amounted to $335 \mathrm{~mm}$, the average temperature was $18.6{ }^{\circ} \mathrm{C}$, the number of days of drought (with relative humidity $\leq 30 \%$ ) - 32, and HTC (Selyaninov hydrothermal coefficient) 1.03. 2017 was little favorable for hydration: during AprilSeptember there were $283 \mathrm{~mm}$ of rainfall, the average temperature amounted to $19.7{ }^{\circ} \mathrm{C}$, the number of drought days has reached 57 , and HTC -0.99 .2018 was acutely arid: rainfall was $235 \mathrm{~mm}$, the average temperature was $20.9^{\circ} \mathrm{C}$, days of drought $-71, \mathrm{HTC}-0.67$. The sum of active temperatures (the period with average daily air temperatures of $10{ }^{\circ} \mathrm{C}$ and higher) for the growing season in 2016 was $3546{ }^{\circ} \mathrm{C}$, in $2017-3166{ }^{\circ} \mathrm{C}$, in $2018-3507$ ${ }^{\circ} \mathrm{C}$. 


\section{Results and discussion}

Weather conditions had a significant impact on the formation of the level of grain productivity of the studied sorghum varieties.

In a favorable 2016 year, modern high-intensity early-ripening and mid-early hybrids of domestic and foreign selection most fully revealed their genetic potential of productivity (table 2), exceeding the yield level of 6.0-6.5 t/ha of grain $\left(\mathrm{SSD}_{05}=0.29 \mathrm{t} / \mathrm{ha}\right)$. Despite the dry conditions in 2017 the crop productivity was at a fairly high level and the most productive cultivars have delivered the grain harvest at 6.0-6.5 t/ha $\left(\operatorname{SSD}_{05}=0.32 \mathrm{t} / \mathrm{ha}\right)$. However, in extremely dry conditions in 2018 , the cultivation of the earliest varieties and hybrids of the crop was more effective, which provided a maximum grain yield of 5.0-5.5 $\mathrm{t} / \mathrm{ha}\left(\mathrm{SSD}_{05}=0.30 \mathrm{t} / \mathrm{ha}\right)$.

Table 2. Influence of weather conditions and varietal characteristics

for the duration of the growing season and the yield of grain sorghum for 2016-2018.

\begin{tabular}{|c|c|c|c|c|c|c|c|c|}
\hline \multirow{2}{*}{ Variety denomination } & \multicolumn{2}{|c|}{2016} & \multicolumn{2}{|c|}{2017} & \multicolumn{2}{|c|}{2018} & \multicolumn{2}{|c|}{ Average } \\
\hline & $1 *$ & 2 & 1 & 2 & 1 & 2 & 1 & 2 \\
\hline Prime (USA) & 90 & 4.90 & 90 & 4.54 & 92 & 5.37 & 91 & 4.94 \\
\hline Dash E (USA) & 103 & 6.10 & 99 & 5.88 & 98 & 4.70 & 100 & 5.56 \\
\hline Sprint W 341/22 (USA) & 115 & 7.06 & 105 & 5.23 & 101 & 4.58 & 107 & 5.62 \\
\hline Swift 380/79 (USA) & 106 & 6.97 & 102 & 6.01 & 100 & 4.94 & 103 & 5.97 \\
\hline Nash (Crimea) & 103 & 5.81 & 98 & 5.16 & 99 & 4.42 & 100 & 5.13 \\
\hline Krymbel (Crimea) & 91 & 4.86 & 96 & 5.06 & 90 & 3.73 & 92 & 4.55 \\
\hline Progress (Crimea) & 102 & 4.30 & 102 & 4.54 & 99 & 4.17 & 101 & 4.34 \\
\hline Krupinka 10 (Crimea) & 112 & 5.22 & 103 & 5.72 & 102 & 4.53 & 106 & 5.16 \\
\hline Dniprovskyi 39 (Dnieper) & 89 & 3.74 & 102 & 3.83 & 99 & 3.57 & 97 & 3.71 \\
\hline Lan 59 (Dnieper) & 111 & 6.16 & 104 & 5.70 & 94 & 5.11 & 103 & 5.66 \\
\hline Odesskyi 205 (Odessa) & 106 & 6.24 & 100 & 5.21 & 100 & 4.61 & 102 & 5.35 \\
\hline Odesskyi 302 (Odessa) & 101 & 5.03 & 104 & 4.92 & 106 & 3.88 & 104 & 4.61 \\
\hline Druzhnyi (Odessa) & 103 & 5.24 & 105 & 4.95 & 105 & 4.04 & 104 & 4.74 \\
\hline Atlant (Odessa) & 104 & 5.42 & 105 & 5.27 & 105 & 3.86 & 105 & 4.85 \\
\hline Izumrud (Odessa) & 104 & 5.42 & 106 & 4.88 & 105 & 3.90 & 105 & 4.73 \\
\hline Darunok (Odessa) & 105 & 5.37 & 108 & 5.60 & 106 & 4.29 & 106 & 5.09 \\
\hline Friggo (France) & 88 & 4.75 & 91 & 4.84 & 91 & 5.01 & 90 & 4.87 \\
\hline Burggo (France) & 99 & 6.58 & 98 & 5.55 & 100 & 4.89 & 99 & 5.67 \\
\hline Stingg (France) & 100 & 5.95 & 99 & 5.34 & 101 & 4.62 & 100 & 5.30 \\
\hline Brigga (France) & 101 & 5.91 & 102 & 5.92 & 100 & 4.54 & 101 & 5.46 \\
\hline Oggana (France) & 100 & 6.36 & 102 & 6.00 & 100 & 4.96 & 101 & 5.77 \\
\hline Targga (France) & 103 & 6.90 & 105 & 5.80 & 103 & 4.62 & 104 & 5.77 \\
\hline Queyras (France) & 102 & 6.06 & 103 & 6.11 & 98 & 5.68 & 101 & 5.95 \\
\hline Solarius (France) & 112 & 6.92 & 105 & 6.62 & 100 & 5.11 & 106 & 6.22 \\
\hline Fulgus (France) & 115 & 6.61 & 105 & 5.66 & 101 & 4.96 & 107 & 5.74 \\
\hline Cosmosol (Austria) & 107 & 5.11 & 96 & 5.28 & 98 & 4.76 & 100 & 5.05 \\
\hline PR88Y20 (Austria) & 114 & 6.03 & 105 & 6.01 & 101 & 6.07 & 107 & 6.04 \\
\hline Zernogradsk. 88 (Russia) & 84 & 4.45 & 90 & 5.12 & 92 & 4.82 & 89 & 4.80 \\
\hline Orlovskoye (Russia) & 79 & 4.88 & 87 & 4.99 & 88 & 3.82 & 85 & 4.56 \\
\hline Velikan (Russia) & 100 & 5.18 & 92 & 4.79 & 94 & 4.20 & 95 & 4.72 \\
\hline Luchistoye (Russia) & 93 & 5.27 & 93 & 4.63 & 92 & 4.57 & 93 & 4.82 \\
\hline Khazine 28 (Russia) & 105 & 4.10 & 91 & 4.62 & 96 & 4.17 & 97 & 4.30 \\
\hline Zersta 97 (Russia) & 100 & 5.50 & 96 & 5.02 & 102 & 4.85 & 99 & 5.12 \\
\hline Kim (Russia) & 113 & 4.38 & 94 & 5.08 & 105 & 4.89 & 104 & 4.78 \\
\hline Bianca (India) & 115 & 6.26 & 111 & 6.37 & 104 & 5.36 & 110 & 6.00 \\
\hline Puma star (India) & 112 & 7.27 & 108 & 6.62 & 103 & 5.65 & 108 & 6.51 \\
\hline Yankee (India) & 101 & 5.71 & 95 & 5.28 & 91 & 4.98 & 96 & 5.32 \\
\hline
\end{tabular}




\begin{tabular}{|c|c|c|c|c|c|c|c|c|}
\hline Bounty (India) & 128 & $\mathbf{7 . 7 2}$ & 114 & $\mathbf{6 . 1 9}$ & 108 & $\mathbf{4 . 8 4}$ & 117 & $\mathbf{6 . 2 5}$ \\
\hline$\overline{\mathrm{x}} \pm \mathrm{S} \overline{\mathrm{x}}$ & $103.0 \pm$ & $5.68 \pm$ & $100.3 \pm$ & $5.38 \pm$ & $99.2 \pm$ & $4.66 \pm$ & $100.9 \pm$ & $5.24 \pm$ \\
& 1.6 & 0.15 & 1.0 & 0.10 & 0.8 & 0.09 & 1.0 & 0.10 \\
\hline $\mathrm{S}$ & 9.68 & 9.43 & 6.34 & 6.24 & 5.09 & 5.70 & 6.40 & 6.27 \\
\hline $\mathrm{V}$ & 9.39 & 16.60 & 6.32 & 11.61 & 5.13 & 12.23 & 6.34 & 11.97 \\
\hline $\mathrm{r} \pm \mathrm{S}_{\mathrm{r}}$ & $0.61 \pm 0.13$ & \multicolumn{2}{|c|}{$0.58 \pm 0.14$} & $0.01 \pm 0.17$ & $0.58 \pm 0.14$ \\
\hline $\mathrm{t}_{\mathrm{r}}$ fact. & \multicolumn{2}{|c|}{4.62} & \multicolumn{2}{|c|}{4.25} & \multicolumn{2}{c|}{0.04} & \multicolumn{2}{c|}{4.27} \\
\hline $\mathrm{t}_{\mathrm{r}}$ tabl. & \multicolumn{2}{|c|}{2.02} & \multicolumn{2}{|c|}{2.02} & \multicolumn{2}{c|}{2.02} \\
\hline
\end{tabular}

Note*. Table 2, column 1 shows the growing season (days), and column 2 shows the grain yield of the studied sorghum varieties, $\mathrm{t} / \mathrm{ha}$

The average HTC was 0.14 (desert zone) with a long-term climatic norm of 0.81 , the average air temperature was $23.0^{\circ} \mathrm{C}$ (norm $20.4{ }^{\circ} \mathrm{C}$ ), the amount of precipitation was 16.3 $\mathrm{mm}$ (norm $-82 \mathrm{~mm}$ ), and the number of days with a relative humidity of $30 \%$ or less reached 32 with a norm of 12.5 days. Under these weather conditions, medium-early and mid-season varieties and hybrids of sorghum failed to realize their potential productivity. Due to the hot and dry weather in August 2018, the average weight of 1000 grains for the studied varieties was only $20.2 \mathrm{~g}$, while in a dry 2017 - $23.6 \mathrm{~g}$, and in a favorable 2016 $27.7 \mathrm{~g}$. The duration of the growing season in 2016 and 2017 had a direct average reliable correlation with the level of yield of the studied varieties of grain sorghum ( $\mathrm{r}=$ $0.61 \pm 0.13 \ldots 0.58 \pm 0.14)$ and was completely absent in hot and dry $2018(\mathrm{r}=0.01 \pm 0.17)$. A significant negative correlation between the yield and the density of the productive stem was obtained only in the conditions of 2017, and on average for 3 years this correlation was insignificant (table 3).

Table 3. Correlation of indicators of the sorghum crop structure with its yield for 2016-2018

\begin{tabular}{|c|c|c|c|c|c|c|c|c|c|c|c|c|c|}
\hline \multirow[b]{2}{*}{ 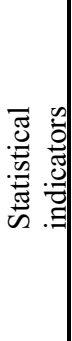 } & \multirow[b]{2}{*}{ 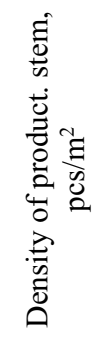 } & \multirow[b]{2}{*}{ 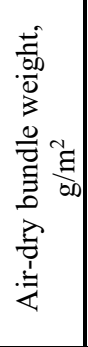 } & \multirow[b]{2}{*}{ 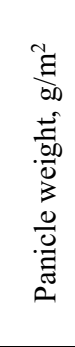 } & \multirow[b]{2}{*}{ 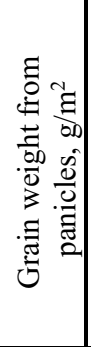 } & \multirow[b]{2}{*}{ 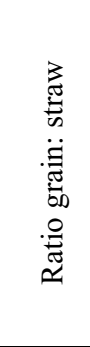 } & \multirow[b]{2}{*}{ 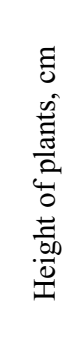 } & \multirow[b]{2}{*}{ 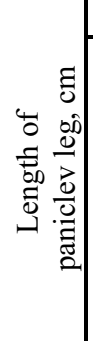 } & \multicolumn{4}{|c|}{ Panicle structure } & \multirow[b]{2}{*}{ 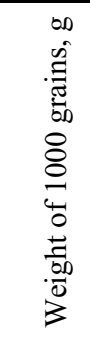 } & \multirow[b]{2}{*}{ 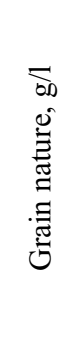 } \\
\hline & & & & & & & & $\begin{array}{l}E \\
0 \\
\tilde{E} \\
\overline{00} \\
\tilde{\Xi}\end{array}$ & 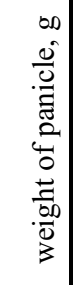 & 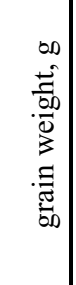 & 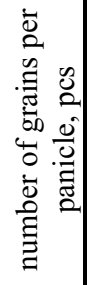 & & \\
\hline \multicolumn{14}{|c|}{ 16, favorable year (the average yield of sorghum in the experimental variants is $5.68 \mathrm{t} / \mathrm{ha}$ ) } \\
\hline$\widehat{\mathrm{x}}$ & 17.5 & 1516 & 786 & 641 & $1: 1.18$ & 103.2 & 8.79 & 23.5 & 44.5 & 38.1 & 1367 & 27.65 & 795 \\
\hline $\mathrm{V}$ & 17.3 & 17.1 & 19.6 & 20.2 & 36.4 & 15.5 & 68.5 & 11.6 & 30.7 & 25.8 & 27.0 & 16.2 & 2.8 \\
\hline$S$ & 0.49 & 42.1 & 25.1 & 21.0 & 0.07 & 2.59 & 0.98 & 0.44 & 2.21 & 1.55 & 59.9 & 0.73 & 3.62 \\
\hline $\mathrm{r}$ & 0.09 & 0.53 & 0.86 & 0.89 & -0.54 & -0.31 & 0.09 & -0.04 & 0.63 & 0.69 & 0.59 & 0.14 & 0.36 \\
\hline $\mathrm{S}_{\mathrm{r}}$ & 0.17 & 0.14 & 0.08 & 0.08 & 0.14 & 0.16 & 0.17 & 0.17 & 0.13 & 0.12 & 0.13 & 0.17 & 0.16 \\
\hline $\mathrm{t}_{\mathrm{r}} *$ & 0.56 & 3.75 & 10.33 & 11.78 & 3.89 & 1.92 & 0.51 & 0.24 & 4.86 & 5.74 & 4.40 & 0.83 & 2.31 \\
\hline \multicolumn{14}{|c|}{2017 , dry year (average yield according to the experimental variants $-5.38 \mathrm{t} / \mathrm{ha}$ ) } \\
\hline$\overline{\mathrm{x}}$ & 16.2 & 1148 & 693 & 547 & 1:0.84 & 110.7 & 8.37 & 25.0 & 44.2 & 35.5 & 1548 & 23.64 & 794 \\
\hline $\mathrm{V}$ & 20.9 & 17.3 & 17.7 & 17.0 & 34.3 & 15.0 & 57.2 & 15.6 & 31.1 & 32.4 & 35.9 & 21.7 & 3.0 \\
\hline S & 0.55 & 32.2 & 19.9 & 15.10 & 4.72 & 2.69 & 0.78 & 0.63 & 2.23 & 1.87 & 90.1 & 0.83 & 3.86 \\
\hline $\mathrm{r}$ & -0.35 & 0.31 & 0.55 & 0.59 & -0.35 & -0.33 & -0.34 & \begin{tabular}{|l|}
0.30 \\
\end{tabular} & 0.52 & 0.49 & 0.53 & -0.13 & 0.45 \\
\hline $\mathrm{S}_{\mathrm{r}}$ & 0.16 & 0.16 & 0.14 & 0.14 & 0.16 & 0.16 & 0.16 & 0.16 & 0.14 & 0.15 & 0.14 & 0.17 & 0.15 \\
\hline $\mathrm{t}_{\mathrm{r}}$ & 2.22 & 1.97 & 3.99 & 4.35 & 2.24 & 2.11 & 2.15 & 1.86 & 3.63 & 3.36 & 3.78 & 0.81 & 3.04 \\
\hline
\end{tabular}




\begin{tabular}{|c|c|c|c|c|c|c|c|c|c|c|c|c|c|}
\hline$\overleftarrow{\mathrm{x}}$ & 15.8 & 1013 & 643 & 506 & $1: 0.72$ & 109.1 & 6.88 & 25.0 & 43.2 & 33.0 & 1714 & 20.20 & 779 \\
$\mathrm{~V}$ & 16.32 & 13.4 & 17.7 & 16.1 & 26.2 & 15.3 & 63.6 & 15.0 & 27.1 & 25.4 & 31.3 & 22.8 & 6.0 \\
\hline $\mathrm{S}$ & 0.42 & 22.1 & 18.4 & 13.3 & 0.03 & 2.71 & 0.71 & 0.61 & 1.90 & 1.36 & 87.2 & 0.75 & 7.55 \\
\hline $\mathrm{r}$ & -0.27 & 0.63 & 0.56 & 0.72 & -0.28 & -0.46 & -0.09 & 0.37 & 0.55 & 0.54 & 0.57 & -0.37 & 0.08 \\
\hline $\mathrm{S}_{\mathrm{r}}$ & 0.16 & 0.13 & 0.14 & 0.12 & 0.16 & 0.15 & 0.17 & 0.16 & 0.14 & 0.14 & 0.14 & 0.15 & 0.17 \\
\hline $\mathrm{t}_{\mathrm{r}}$ & 1.66 & 4.87 & 4.08 & 6.29 & 1.73 & 3.10 & 0.54 & 2.37 & 3.97 & 3.86 & 4.14 & 2.39 & 0.48 \\
\hline \multicolumn{10}{|c|}{ Average for the } \\
\hline$\overline{\mathrm{x}}$ & 16.5 & 1226 & 708 & 565 & $1: 0.91$ & 107.7 & 8.01 & 24.5 & 44.3 & 35.2 & 1519 & 23.83 & 789 \\
\hline $\mathrm{V}$ & 13.4 & 12.5 & 13.1 & 13.6 & 24.9 & 14.2 & 40.0 & 12.4 & 22.3 & 21.8 & 26.8 & 17.5 & 3.3 \\
\hline $\mathrm{S}$ & 0.36 & 24.79 & 15.0 & 12.47 & 0.04 & 2.48 & 0.52 & 0.49 & 1.60 & 1.24 & 65.9 & 0.68 & 4.27 \\
\hline $\mathrm{r}$ & -0.28 & 0.56 & 0.85 & 0.86 & -0.50 & -0.47 & -0.29 & 0.20 & 0.70 & 0.69 & 0.64 & -0.17 & 0.41 \\
\hline $\mathrm{S}_{\mathrm{r}}$ & 0.16 & 0.14 & 0.09 & 0.08 & 0.14 & 0.15 & 0.16 & 0.16 & 0.12 & 0.12 & 0.13 & 0.16 & 0.15 \\
\hline $\mathrm{t}_{\mathrm{r}}$ & 1.74 & 4.01 & 9.58 & 10.17 & 3.49 & 3.18 & 1.84 & 1.21 & 5.81 & 5.59 & 4.94 & 1.06 & 2.67 \\
\hline
\end{tabular}

$\left(\mathrm{t}_{\mathrm{r}}{ }^{*}\right.$ - Student's actual criterion, to5 table - Student's tabular criterion $\left.=2.025\right)$

With an increase in the plant weight from $1 \mathrm{~m}^{2}$, the panicles weight and the weight of grain from panicles, the yield naturally increased (on average for 3 years, respectively, $r=$ $0.56,0.85$ and 0.86 ).

In the studied samples, when the yield had increased, the height of plants naturally decreased (correlation coefficients $r=-0.50$ and $r=-0.47$, respectively) (Fig. 1).

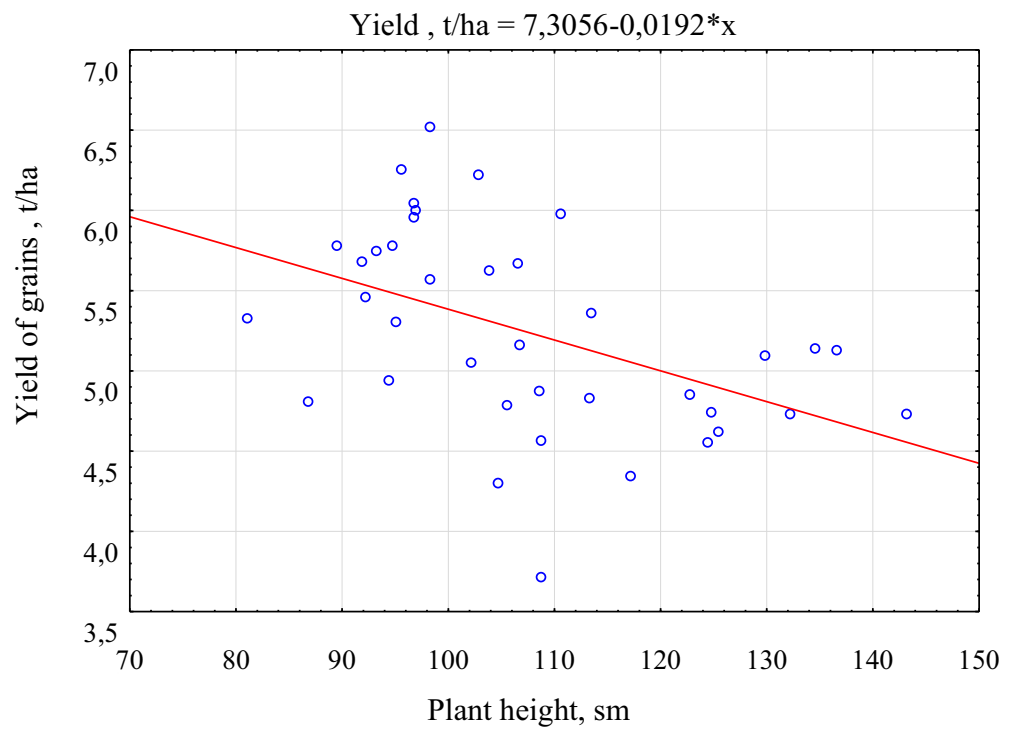

Fig. 1. Relationship between yield and height of sorghum plants, 2016-2018

The number of grains in the sorghum panicle had an average reliable direct correlation $(\mathrm{r}=0.64 \pm 0.13)$ with the sorghum yield (Fig. 2).

According to economically valuable characteristics - "panicle weight" and "grain weight per panicle", the correlation coefficients with crop yield $r=0.70$ and $r=0.69$ were obtained. The weight of 1000 grains only in the conditions of dry and hot 2018 had a significant negative correlation with the crop yield $(\mathrm{r}=-0.37)$. The average correlation between the grain unit and crop yield was observed only in the most favorable years for 
moisture availability in 2016 and $2017(\mathrm{r}=0.36 \ldots 0.45)$. Panicle leg length and panicle length had no significant correlation with sorghum grain yield.

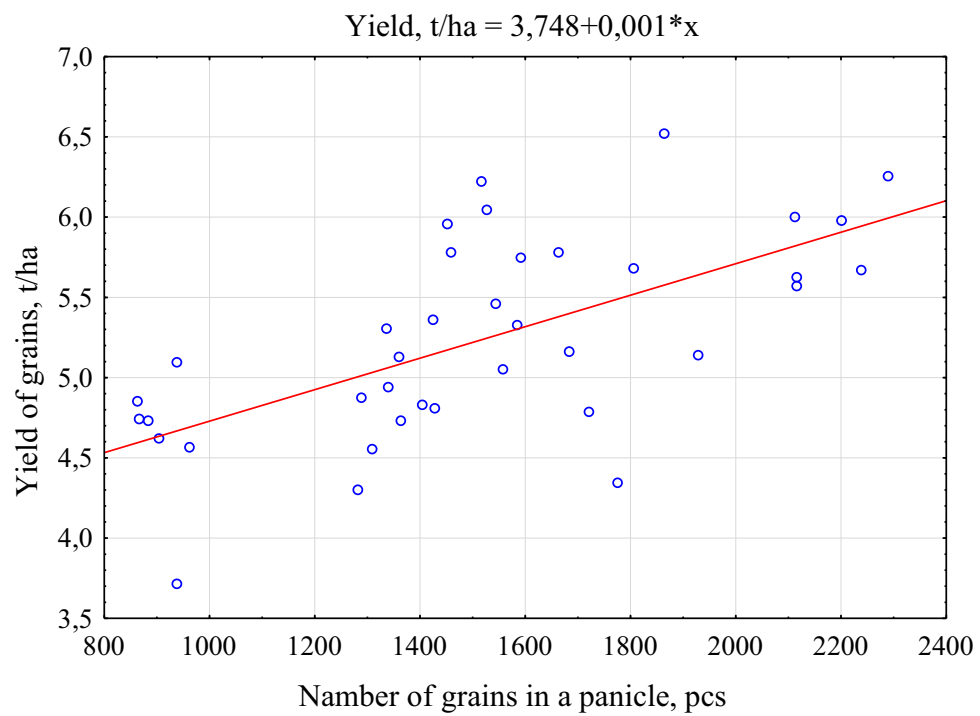

Fig. 2. Relationship between yield and number of grains in a sorghum panicle, 2016-2018

In general, over the years of research the highest yield (at the level of $6.0 \mathrm{t} / \mathrm{ha}$ and more) provided such hybrids: Swift (USA, RICHARDSON SEED company), Queyras (France, EURALIS SEMENCES) - from the early-ripening group; Solarius (France, EURALIS SEMENCES company), PR88Y20 (Austria, PIONEER company), Bianca (India, ADVANTA company), Puma Star (India, ADVANTA company) - from the group of midearly and mid-season hybrid Bounty (India, ADVANTA company). The most adapted and productive (at the level of $5.0 \mathrm{t} / \mathrm{ha}$ or more) among sorghum varieties were the following: Krupinka 10 (Ukraine), Odesskyi 205 (Ukraine), Darunok (Ukraine), Zersta 97 (Russia).

\section{Conclusions}

1. The yield level of the studied varieties of grain sorghum on average for 2016-2018 years directly depended on the duration of the growing season of the crop $(r=0.58 \pm 0.14)$.

2. The density of the productive stem of sorghum crops, with fluctuations in varietal samples over the years of experience from 11 to 25 stems per $1 \mathrm{~m}^{2}$, did not have a reliable correlation with the yield $(r=-0.28 \pm 0.16)$ and only in the dry 2017 it was weak and significantly negative $(\mathrm{r}=-0.35 \pm 0.16)$.

3. The strongest correlation was observed between panicle weight, weight of grain from panicle, its grains/ear, and sorghum yield $(\mathrm{r}=0.70 ; 0.69 ; 0.64)$.

4. The weight of 1000 grains did not correlate with the yield level of the studied varieties $(-0.17 \pm 0.16)$.

5. During the years of research, Swift and Queyras had the highest grain productivity (6.0 t/ha of grain or more) among early-ripening hybrids; among the group of medium-early hybrids - Solarius, PR88Y20, Bianca, Puma Star; among mid-season hybrids - Bounty hybrid. The most productive (5.0 t/ha and more grain) varieties were Odesskiy 205, Krupinka 10, Darunok, Zersta 97. 


\section{References}

1. V.V. Kovtunov, Grain farming in Russia, 3, 47-49 (2018)

2. Food and Agricultural Organization (FAO) (FAOSTAT, 2005) http://faostat.fao.org/faostat/

3. M. Galiba, R.D. Waniska, L.W. Rooney, F.R. Miller, J. Cereal Sci., 7, 183-193 (1988)

4. A.V. Baranovsky, Proceedings of the Orenburg State Agrarian University, 1(81), 28-33 (2020)

5. Mamoudou H. Dicko, Harry Gruppen, Alfred S. Traoré1, Alphons G. J. Voragen and Willem J. H. van Berkel, African Journal of Biotechnology, 5(5), 384-395, (2006) http://www.academicjournals.org/AJB

6. A.V. Baranovsky, T.M. Kosogova, S.I. Kapustin, A.S. Kapustin, Bioscience Research, 17(1), 228-234 (2020)

7. N.A. Shepel, Sorghum (Volgograd: Press Committee, 1994)

8. Yu.M. Vlasova, Agroclimatic guide to the Lugansk region (1986-2005), (Lugansk:

LLC "Virtual Reality", 2011)

9. A.V. Baranovsky, A.I. Denisenko, N.I. Dranishchev et al., Recommendations on the technology of growing and using sorghum crops (Lugansk: LLC "Kopir-center Lugansk", 2014)

10. A.V. Alabushev, Technological methods of cultivation and use of sorghum (Rostovon-Don, 2007) 